\title{
More important than life and death
}

\author{
Kamran Abbasi international editor
}

The BMJ

It is an interesting time to propose collaboration as a solution for the NHS. The United Kingdom may decide to leave the European Union, with unknown consequences for science and health (doi:10.1136/bmj.i1117). A state of emergency exists in primary care, where GPs are stressed (doi:10.1136/bmj.i693). Health and social care remain dysfunctional (doi:10.1136/bmj. i458). England's health secretary has imposed a new contract on junior doctors (doi:10.1136/bmj.i1129; doi:10.1136/bmj. i1124). You might then reasonably conclude that collaboration isn't in the air. Nor is the cup of goodwill overflowing.

"Sustained effort" might not be the cleverest rallying cry for a demoralised workforce. Yet Hugh Alderwick and Chris Ham argue that collaboration, goodwill, and sustained effort are essential ingredients to rescue the NHS in England from the "biggest crisis in its history" (doi:10.1136/bmj.i1022).

This alarming scenario has come quickly, considering that the Health and Social Care Act was passed a little over three years ago. Few readers will dispute the editorialists' diagnosis of a crisis, but they might question our ability to resolve it. NHS organisations are producing "place based plans," multiyear proposals to meet the needs of local populations. The central challenge is to replace competition, beloved of the Health and Social Care Act, as the main driver of change and to allow collaboration to flourish instead. Alderwick and Ham warn that it is hard for collaboration to succeed in a legislative environment built for competition.
One solution is new care models that integrate services and promote place based collaboration between NHS providers and commissioners, local authorities, and third sector organisations. The logic seems sound, but why should today's new models of care be any more viable than yesterday's? And even if they are, a challenge remains in translating successful small scale initiatives to larger geographies and populations. These collaborations require goodwill and sustained effort. But in an environment where staff are already making sustained effort, and where goodwill has run dry, how likely are we to reach the light at the end of this tunnel?

Perhaps this is an issue of communication? We might be better served adopting the language of football. "The NHS is a funny old game," writes David Barer (doi:10.1136/bmj.i1023), whose home team, incidentally, sits near the bottom of the English Premier League. Just as with football, new formations must be tried, the consequences of any tactical change are impossible to predict, and, importantly, everyone is an expert. To paraphrase Liverpool's legendary manager Bill Shankly, some people believe that health is a matter of life and death, but we can assure you that it is much, much more important than that.

In an environment where staff are already making sustained effort, and where goodwill has run dry, how likely are we to reach the light at the end of this tunnel? 